\title{
A efetivação do direito à educação com qualidade social: o início do contexto pandêmico no estado do Rio Grande do Sul na percepção de gestores escolares
}

\author{
The realization of the right to education with social quality: the beginning of the pandemic context in \\ Rio Grande do Sul in the perception of school managers \\ La réalisation du droit à une éducation de qualité sociale: le début du contexte pandémique à Rio \\ Grande do Sul dans la perception des directeurs d'école
}

Resumo: O presente artigo busca evidenciar os primeiros movimentos da relação estadoescola no contexto da pandemia do novo coronavírus, no Estado do Rio Grande do Sul, à luz da efetivação do direito à educação com qualidade social na perspectiva de gestores escolares. Como estratégia metodológica na produção de dados utilizamos a abordagem qualitativa junto a pesquisa bibliográfica e documental, incluindo entrevistas semiestruturadas com diretores de escolas públicas. O processo analítico se deu pela análise textual discursiva com viés dialético-materialista. Os resultados indicam o complexo cenário de efetivação do direito à educação com qualidade social, especialmente pela forma como o engendramento político não se consubstancia na materialidade do cotidiano escolar.

Palavras-Chave: Direito à Educação. Qualidade Social da Educação. Gestão Educacional. Contex to Pandêmico.

\begin{abstract}
This article seeks to highlight the first movements of the state-school relationship in the context of the new coronavirus pandemic in the State of Rio Grande do Sul in light of the realization of the right to education with social quality from the perspective of school managers. As a methodological strategy in the production of data, we used a qualitative approach together with bibliographic and documentary research, including semi-structured interviews with public school principals. The analytical process took place through discursive textual analysis with a dialectical-materialist bias. The results indicate the complex scenario for the realization of the right to education with social quality, especially because of the way in which political engendering is not substantiated in the materiality of everyday school life.
\end{abstract}

Key words: Right to Education. Social Quality of Education. Educational Management. Pandemic Context.

\footnotetext{
Abstrait: Cet article cherche à mettre en évidence les premiers mouvements de la relation État-école dans le contexte de la pandémie du nouveau coronavirus dans l'État du Rio Grande do Sul, à la lumière de la réalisation du droit à une éducation de qualité sociale, du point de

${ }^{1}$ Doutor em Educação pela Universidade do Vale do Rio dos Sinos (UNISINOS), Professor Colaborador do Departamento de Pedagogia da Universidade Estadual de Ponta Grossa (DEPED/UEPG). E-mail: julian.diogo@gmail.com. Lattes. http://lattes.cnpq.br/7808693167946729. ORCID: https:// orcid.org/o000-0001-8507-6538.
} 
vue des directeurs d'école. Comme stratégie méthodologique dans la production de données, nous avons utilisé une approche qualitative ainsi que des recherches bibliographiques et documentaires, y compris des entretiens semi-directifs avec des directeurs d'écoles publiques. Le processus analytique a eu lieu à travers une analyse textuelle discursive, avec un biais dialectique-matérialiste. Les résultats indiquent le scénario complexe de la réalisation du droit à une éducation de qualité sociale, notamment en raison de la manière dont l'engendrement politique n'est pas consubstantiel dans la matérialité de la vie scolaire quotidienne.

Mots clés: Droit à l'éducation. Qualité Sociale de l'éducation. Gestion Pédagogique. Contexte Pandémique.

Recebido em: 07 de julho de 2021

Aceito em: 01 de agosto de 2021

\section{Introdução}

A pandemia trazida com o surto mundial do novo Coronavírus (SARS-CoV-2), causador da COVID-19, trouxe consigo uma série de impactos em diferentes dimensões da tessitura social nos mais variados contextos do globo (FREITAS; NAPIMOGA; DONALISIO, 2020). Estudantes ao redor do mundo tiveram suas aulas substituídas pelo ensino remoto emergencial como uma alternativa na continuidade da promoção de um trânsito formativo ininterrupto, de maneira equitativa nas instituições de ensino (ALVES, 2020). A estratégia da implementação emergencial do ensino remoto surge no intuito de diminuir o impacto da pandemia no contexto educacional nacional e internacional, este marcado por profundas desigualdades e vulnerabilidades estruturais.

Jakimiui (2020, p. 97), ao indicar os contornos das limitações do desenvolvimento do trabalho pedagógico no contexto da pandemia, destaca que a sua mediação através das tecnologias trouxe forte impacto na sua consecução considerando a "dificuldade do acesso e utilização dos recursos tecnológicos, tanto pelos professores quanto estudantes, torna-se um desafio”, reconhecendo ainda a baixa adesão das comunidades escolares a cultura do ensino remoto, ponderando "que a permanência das pessoas em casa provocada pelas medidas de distanciamento social, resulta em mudanças nas rotinas interferindo nas múltiplas realidades sociais" (ibidem, p. 98).

Nesse cenário o direito à educação não pode ser compreendido como apenas uma mera opção política, pelo contrário, é preciso que seja considerado uma conquista de demandas sociais em nosso país, a partir do reconhecimento da importância da educação como um importante elemento no desenvolvimento da nação e da sua dimensão social presente no seu entendimento como um bem público (OLIVEIRA, 2001). Essa perspectiva expõe de forma direta as demandas 
de classes sociais na emergência da possibilidade de uma "participação na vida econômica, social e política" da nação, assim temos a educação como um importante "canal de acesso aos bens sociais e à luta política e como tal um caminho também de emancipação do indivíduo (...) [e também] de mobilidade social e de integração na ordem social” (CURY, 2010, p. 569).

As questões relativas à qualidade da educação se tornam pujantes nesse contexto confuso e conturbado da pandemia do novo coronavírus no que se refere a sua efetivação por parte dos entes federados. Não nos referimos a uma tipologia de qualidade da educação vinculada à produção de índices estandardizados para avaliações institucionais ou mesmo as de larga escala, nos referimos a um tipo de qualidade de difícil mensuração, mas de primordial importância se considerarmos as vicissitudes da desigualdade educacional brasileira e as dimensões de justiça social e educação emancipadora: a qualidade social da educação. Esta tipologia focaliza seus esforços no "aspecto social, cultural e ambiental da educação, em que se valoriza não só o conhecimento simbólico, mas também o sensível e o técnico” (GADOTTI, 2010, p. 1), de forma a estimular a "promoção e atualização histórico-cultural [dos sujeitos], em termos de formação sólida, crítica, ética e solidária, articulada com políticas públicas de inclusão e resgate social”, como apontam Dourado e Fernandes (2009, p. 211 ).

Pensemos neste cenário à luz da atuação das equipes gestoras das redes públicas educacionais e as limitações da atuação do Estado no desenvolvimento de estratégias que possibilitem uma leitura da fração da realidade em que a qualidade social da educação ganha novos contornos, a partir do incremento do cenário do contexto pandêmico no qual estamos inseridos. Considerando ainda o que está posto na Medida Provisória Federal n 934/20 que aponta normas excepcionais sobre o ano letivo da educação brasileira decorrente das medidas para enfrentamento da COVID-19 (BRASIL, 2020a) e o parecer do Conselho Nacional de Educação $n^{\circ}$ 05/20 que reorganiza os calendários escolares e abre a possibilidade de cômputo de atividades não presenciais (BRASIL, 2020b), temos aqui os primeiros documentos oficiais que trouxeram baila os encaminhamentos da educação no momento particular que vivemos.

Este estudo exposto neste artigo busca evidenciar os primeiros movimentos da relação estado-escola no contex to da pandemia do novo coronavírus, no Estado do Rio Grande do Sul, à luz da efetivação do direito à educação com qualidade social na perspectiva de gestores escolares. Para isso, nos utilizamos da abordagem qualitativa (CERVO; BERVIAN, 2002) no entendimento do fenômeno, tendo na produção dos dados a combinação da pesquisa bibliográfica (FONSECA, 2002) e documental (CELLARD, 2008) na construção do contexto e do argumento da investigação, fora utilizada a estratégia das entrevistas semiestruturadas (HAGUETTE, 2003) com integrantes de equipes diretivas de escolas públicas do estado. No processo analítico utilizamos a análise textual discursiva (MORAES, GALIAZZI; 2011). 
A pandemia do novo coronavírus desvelou e evidenciou a fragilidade de diferentes sistemas educacionais em torno do globo, aqui não indicamos apenas a uma impermanência de sustentação teórico-metodológica, mas sim uma falta no campo estrutural-operacional na consecução das atividades pedagógicas. O atendimento emergencial disponibilizado aos estudantes, em um primeiro momento, buscou garantir a oferta educacional da melhor maneira possível, várias estratégias políticas foram desenvolvidas. Todavia a "política” idealizada é sempre (re)significa na sua relação com os sujeitos, no caso do Brasil, o descompasso entre ações de enfrentamento a crise na relação entre os entes federados fez com que as necessidades do atendimento educacional fossem relativizadas, especialmente ao não reconhecimento das desigualdades e vulnerabilidades sociais do país.

\section{O direito à educação e a qualidade social da educação: alguns apontamos necessários}

O direito a educação é uma conquista recente no Brasil, tendo como marco a Constituição Federal de 1988, até então o Estado se desonerava da obrigação da garantia de uma educação de qualidade a todos os brasileiros, dentro da perspectiva de uma educação pública associada a uma noção assistencialista e de amparo aqueles sujeitos que não tinham condições de custear esse “serviço" (DUARTE, 2007). Investigações do campo da história da educação acabam indicando movimentos históricos, políticos e sociais que elevaram o patamar do direito à educação na sua relação direta com o papel do Estado, iniciando pelo período colonial quando a educação era entendida um processo instrumentalizado de transmissão de conhecimentos; passando pelo período de instauração da República (1889) onde a educação passou a ser regida sob os princípios da centralização, da formalização e do autoritarismo; e chegando ao momento em que vivemos em que o reconhecimento das desigualdades e vulnerabilidades estruturais são fatores condicionantes da necessidade da garantia da oferta da educação pública, gratuita e de qualidade para todos os cidadão brasileiros (FARENZENA, 2010).

O direito à educação está presente na Declaração Universal dos Direitos Humanos (ONU, 1948), inspirando várias nações a incorporarem essa noção junto às suas constituições. No Brasil a educação como direito emerge a partir de alguns marcos políticos institucionais, destacamos aqui a Constituição Federal (BRASIL, 1988), mais especificamente em ser Art. $6^{\circ}$ ao apontar a educação como um direito social, juntamente com a saúde, a alimentação, o trabalho, a moradia, o transporte, o lazer, a segurança, a previdência social, a proteção à maternidade e à infância, a assistência aos desamparados.

A educação no cenário construção igualitária de uma sociedade democrática e justa, emerge como um direito inalienável devendo ser ofertado a todas e todos, não se engendra apenas como um direito da pessoa, mas sim como um dos seus elementos constitutivos. No Art. $205^{\circ}$ da Carta 
Magna: “A educação, direito de todos e dever do Estado e da família, será promovida e incentivada com a colaboração da sociedade, visando ao pleno desenvolvimento da pessoa, seu preparo para o exercício da cidadania e sua qualificação para o trabalho” (BRASIL, 1988).

A Lei de Diretrizes e Bases da Educação Nacional - Lei Federal nº 9.394/96, ratifica o que preconiza os Art. $6^{\circ}$ e $205^{\circ}$ da Constituição Federal ao indicar em seu Art. $1^{\circ}$ "A educação abrange os processos formativos que se desenvolvem na vida familiar, na convivência humana, no trabalho, nas instituições de ensino e pesquisa, nos movimentos sociais e organizações da sociedade civil e nas manifestações culturais” (BRASIL, 1996). A Lei de Diretrizes e Bases da Educação ainda estabelece na força da Lei os princípios e os deveres do Estado em relação à educação escolar pública no seu Art. $206^{\circ}$, definindo as responsabilidades, em regime de colaboração, entre a União, os Estados, o Distrito Federal e os Municípios, indicados no Art. $208^{\circ}$ (ibidem).

A educação como direito de todos e dever do Estado se mostra como um grande desafio na conjuntura brasileira, é importante que entendamos que a sua efetivação não acontece apenas pela sua escritura na lei, importante considerarmos que no Brasil o processo histórico de consolidação da nação possui a presença marcada das desigualdades e menosprezo as vulnerabilidades. O direito à educação não pode ser percebido apenas pelo seu reconhecido no âmbito legal, é necessário que o mesmo de fato se apresente de fato na sua efetivação para todos os cidadãos. Por esse viés o processo educativo emerge como potência na qualificação dos cidadãos, não apenas em vistas da sua inserção no mercado de trabalho, mas para a sua participação junto às dimensões da sociedade. A negação desse direito atua diretamente na não capacidade da exigência e do exercício dos direitos civis, políticos, econômicos e sociais dos sujeitos, dificultando ainda mais a sua participação ativa e consciente na sociedade.

A qualidade social da educação se mostra de formas distintas adequando-se às diferentes realidades educacionais dos sujeitos e das instituições, todavia, possui uma estruturação básica, como apontam Dourado, Oliveira e Santos (2007). Os autores nos auxiliam nesta compreensão ao conceber a qualidade social da educação como "um processo de atualização histórico-cultural em termos de uma formação sólida, crítica, ética e solidária, articulada com políticas públicas de inclusão e de resgate social” (ibidem, p. 15). A qualidade em educação à luz da realidade social possibilita aos sujeitos o exercício efetivo da cidadania e da democracia neste país, caracterizado pela imensa desigualdade social e educacional, transpondo a perspectiva utilitarista da qualidade que apresentasse introjetada no meio educacional (FLACH, 2012).

Podemos destacar como seus elementos constituintes a democratização do acesso, democratização do conhecimento, democratização da gestão, do financiamento e regime de colaboração, e da valorização dos trabalhadores da educação (CAMINI, et al., 2001). 
Alguns eixos indicadores de qualidade social são ainda considerados como uma possibilidade de tradução de uma política educacional alinhada aos princípios políticos vinculados às propostas de governo democráticas e populares, sendo ainda capazes de aglutinar outras políticas setoriais que contribuem para a sua consecução. Esses eixos se mostram junto a quatro dimensões: educação como direito de cidadania; participação popular na gestão; valorização dos trabalhadores em educação; e recursos adequados (FLACH, 2012). Nesse sentido a qualidade social "extrapola a própria escola para envolver toda a sociedade na formação de cidadãos democráticos” (ibidem, p. 10), e temse a sua reflexão necessária no cenário da educação pública brasileira no contexto da pandemia na possibilidade de efetivação do direito à educação.

\section{Estratégias metodológicas}

A metodologia é parte viva, ativa e orgânica do processo de produção do conhecimento, semelhante a Marx (2008), compreendemos esse movimento como possibilidade da leitura de uma realidade que se estabelece como uma construção teórica balizada pelo plano do real e do concreto, onde "a visão do real torna-se uma abstração se não levarmos em consideração os seus elementos constituintes" (FONTOURA, 2021, p. 188). A trajetória de pesquisa corresponde a uma busca pela totalidade de determinações e de relações, este alcance da totalidade se mostra a partir do concreto, possibilitando a construção de conceitos simples que acabam orientando a representação da sua consecução.

O estudo aqui presente busca evidenciar os primeiros movimentos da relação estadoescola no contexto da pandemia do novo coronavírus, no Estado do Rio Grande do Sul, à luz da efetivação do direito à educação com qualidade social na perspectiva de gestores escolares. A investigação que apresentamos se dá pela perspectiva da abordagem qualitativa (CERVO; BERVIAN, 2002), com base na pesquisa bibliográfica (FONSECA, 2002), da pesquisa documental (CELLARD, 2008) e da utilização de entrevistas semiestruturadas junto com 3 (três) diretores de escolas que aderiram a participação nesta pesquisa. O processo analítico se deu a partir da abordagem da Análise Textual Discursiva (MORAES; GALIAZZI, 2011).

A abordagem qualitativa se mostra como uma possibilidade de leitura e compreensão mais integrada do fenômeno estudado para além dos significados que se colocam frente aos nossos olhos, aqueles que se revelam a partir de uma visão um pouco mais sensível e aberta do problema de pesquisa. Assim esta abordagem articula as diferentes percepções dos sujeitos (presentes em distintos suportes), junto a um referencial teórico que permita a compreensão do fenômeno estudado. A pesquisa que utiliza a abordagem qualitativa permite a captura de uma realidade de forma ampla, evidenciando a sua complexidade (CERVO; BERVIAN, 2002). 
A pesquisa bibliográfica é desenvolvida a partir do levantamento de referências teóricas em que os dados empíricos já foram analisados previamente, importante considerar aqui está tipologia de pesquisa "permite ao pesquisador conhecer o que já se estudou sobre o assunto". Assim, este instrumental metodológico contribui nesta investigação no recolhimento de informações e conhecimentos prévios sobre o problema a respeito do qual se procura a resposta (FONSECA, 2002, p. 32). No conjunto dos materiais que integram nosso corpus analítico, buscamos reconhecer as pesquisas e os estudos sobre a temática na aproximação dos movimentos presentes na contextualização dos sentidos e significados da qualidade social da educação atrelada ao direito à educação, buscando ainda a construção do argumento presente nesta investigação, além do contexto no qual o debate sobre o fenômeno analisado se insere no campo de estudos das políticas públicas educacionais.

A pesquisa documental, por sua vez, trouxe-nos subsídios para a leitura do fenômeno a partir das suas implicações junto ao regramento do Estado à noção prescrita na legislação da educação como direito. Esta análise utiliza o suporte documental como estratégia de produção de dados, retratando em alguma medida uma visão de um contexto e um espaço específico no tempo onde a história se desenvolve. Para Cellard (2008, p. 291) os documentos revelam uma "dimensão do tempo à compreensão do social”, onde "tudo o que é vestígio do passado, tudo o que serve de testemunho, é considerado como documento” (ibidem, p. 296). incorporamos em nossas análises atos normativos editados pelo Governo do Estado no primeiro momento da pandemia no estado. Como aponta Fávero e Centenaro (2019), os documentos acabam desvelando as políticas e por sua vez os impactos na vida cotidiana dos sujeitos e instituições. A pesquisa documental semelhante a bibliográfica auxilia no embasamento do contexto da investigação, considerando ainda os elementos do texto legal e a sua (re)significação pelos sujeitos do espaço educativo.

Foram realizadas entrevistas semiestruturadas (HAGUETTE, 2003) com 3 (três) diretores de escolas de educação básica aderentes a esta investigação, integrantes da $1^{\circ}$ Coordenadoria Regional de Educação ( $1^{\text {a }}$ CRE) da Rede Pública de Educação do Estado do Rio Grande do Sul. Foi utilizado como critério de escolha dos sujeitos da pesquisa além da sua disponibilidade em participar da investigação, professores integrantes do efetivo exercício em funções de magistério público gaúcho junto ao quadro de Carreira do Magistério Público Estadual, integrantes de equipes diretivas de escolas públicas (Diretores ou Vice-Diretores) eleitos e atuantes entre o período de 2019 - 2021.

As entrevistas aqui são percebidas como um instrumental potente na leitura de determinada realidade, considerando ainda as entrevistas semiestruturadas como um “processo de interação social” (ibidem, p. 86), onde a partir da relação estabelecida entre 
pesquisador e pesquisado, informações são obtidas através de um roteiro de entrevista constando de uma lista de pontos ou tópicos previamente estabelecidos de acordo com uma problemática central e que deve ser seguida. Este instrumental metodológico oferece um amplo campo de interrogações emergentes, tendo na interação dos sujeitos o meio fundamental para que a produção dos dados ocorra (HAGUETTE, 2003). Em função das medidas de distanciamento social implementadas no combate à pandemia do novo coronavírus, as entrevistas foram realizadas de forma remota - on-line - com o auxílio do serviço de comunicação telemático Google Meet. As entrevistas foram gravadas, transcritas e enviadas para ciência dos participantes da pesquisa, que autorizaram o uso dos seus relatos junto a investigação de pesquisa pelo Termo de Consentimento Livre e Esclarecido. Os dados desta investigação foram produzidos entre os meses de abril e março de 2021 , tendo como base os acontecimentos ocorridos entre os anos de 2019 e 2020.

No processo de análise dos dados produzidos, a Análise Textual Discursiva (MORAES, GALIAZZI; 2011, p. 7), surge como uma "uma metodologia [de análise] de natureza qualitativa com a finalidade de produzir novas compreensões sobre os fenômenos e discurso". Morais (2003, p. 192), concebe esta metodologia como um "processo auto organizado de construção de compreensão em que novos entendimentos emergem de uma sequência recursiva”, que estrutura-se a partir da desconstrução do corpus analítico de forma a possibilitar a sua unitarização em unidades de sentido e por fim o estabelecimento de relações entre os elementos unitários, como potência "na captação do novo emergente em que nova compreensão é comunicada e validada" (ibidem, p. 192).

Os dados foram tabulados e posteriormente analisados a partir das respostas aos questionamentos de pesquisa, organizados e sistematizados pelos princípios da Análise Textual Discursiva com foco no processo de unitarização das respostas seguida do processo de categorização do engendramento dos dados produzidos em um metatexto, ou seja, da redação final exposta dos achados de pesquisa presentes neste manuscrito. Na exposição dos dados os mesmos são apresentados de forma sequenciada a partir das dimensões de análise: organização do trabalho pedagógico, ensino remoto emergencial, formação e instrumentalização docente, precarização do trabalho docente, e por fim, a qualidade da educação.

Evidenciarmos aqui nossa preocupação com os encaminhamentos éticos na produção do conhecimento, o desenvolvimento desta pesquisa atende rigorosamente as determinações da Resolução n ${ }^{\circ}$ 580/18 da Comissão Nacional de Ética em Pesquisa do Conselho Nacional de Saúde (CONEP/CNS), que trata das especificidades éticas das pesquisas nas Ciências Humanas e Sociais e de outras que se utilizam de metodologias próprias dessas áreas, sendo respaldado tanto no processo de produção dos dados, quanto na análise e divulgação dos 
mesmos. Além do Ofício Circular nº 02/2021 de 24 de fevereiro de 2021 da Comissão Nacional de Ética em Pesquisa da Secretaria-Executiva do Conselho Nacional de Saúde do Ministério da Saúde (CNEP/SENS/MS) que dá orientações para procedimentos em pesquisas com qualquer etapa em ambiente virtual.

A chegada da pandemia no estado do Rio Grande do Sul e o desafio da garantia do direito à educação com qualidade social na percepção dos gestores escolares

Em 26 de fevereiro de 2020 temos a confirmação do primeiro caso de COVID-19 no Brasil, na cidade de São Paulo (UNA-SUS, 2020), já em 10 dia de março de 2020, temos a confirmação do primeiro caso de COVID-19 no Estado do Rio Grande do Sul pelo poder público (RIO GRANDE SUL, 2020e). Nesse momento, as escolas da rede estadual já haviam dado início ao ano letivo de 2020, o calendário escolar já indicava o início no dia 18 de fevereiro, conforme o Decreto $\mathrm{n}^{\circ}$ 54.875/19 (RIO GRANDE DO SUL, 2019). Importante destacarmos que a virada do ano letivo de 2019-2020, antes mesmo da pandemia, foi marcada por um intenso debate político e um cenário pouco favorável aos trabalhadores em educação da rede estadual. Em 18 de novembro de 2019, houve a deflagração da greve da categoria contra a retirada de direitos dos trabalhadores a partir da brutal reformulação do plano de carreira. Infelizmente o engendramento político capitaneado pelo Governador do Estado fez com que a pauta de retirada de direitos e enfraquecimento da educação pública fosse implementada no estado, assim, em 14 de janeiro a categoria decide pelo fim da greve (GZH Política, 2020).

Em meio a descredibilização da educação pública, o desestímulo à permanência da carreira docente e a "retomada" do ano letivo de 2019, um novo ingrediente se apresenta em 2020: a pandemia do novo coronavírus, é nesse cenário que a investigação que trazemos provocamos se insere. A suspensão das aulas presenciais junto a rede ocorreu a partir dos Decretos Estaduais $n^{\circ} 55.118 / 20, n^{\circ} 55.154 / 20$ e $n^{\circ}$ 55.220/20 (RIO GRANDE DO SUL, 2020b; 2020c; 2020d) por um período total de 75 (setenta e cinco dias), é neste período de 18/03/2020 a 31/05/2020 que os dados produzidos por esse estudo se referem, ao primeiro momento da pandemia de COVID-19 no estado do Rio Grande do Sul, das primeiras medidas sanitárias e consequentemente as tentativas de escolas da rede em propor estratégias de garantia do direito à educação com qualidade social.

Ao serem questionados a fazem um breve relato sobre este momento de disruptura da rede pública estadual de educação, neste momento de organização do trabalho pedagógico, os diretores foram taxativos quanto ao sentimento que carregaram nesse período, especialmente no que toca a operacionalização do funcionamento da escola, pois a suspensão das atividades escolas se colocou sobre o regime presencial, não sobre a sua própria funcionalidade. Em 
absoluto as atividades escolares foram interrompidas, apenas "adequaram-se" do presencial para o emergencial remoto, tendo como orientação primeira o parecer $n^{\circ} 01 / 20$ do Conselho Estadual de Educação (RIO GRANDE DO SUL, 2020a).

Simplesmente ficamos abandonados, ninguém sabia o que fazer e como fazer, não estou falando somente dos meus pares, falo do governo! Aulas suspensas não foram sinônimo de aulas canceladas, a suspensão era das atividades presenciais, de alguma maneira tínhamos que fazer a escola continuar funcionando (Diretor da Escola $\beta$ ).

As equipes diretivas sem nenhuma orientação clara do Governo do Estado em como encaminhar o "novo cotidiano" escolar, precisou voltar-se para si e encontrar formas de garantia do direito à educação com seus recursos existentes. Não havia nesse momento nenhum plano de contingência operacional, este foi desenvolvido a posteriori. Na executabilidade das atividades escolares, as instituições de ensino se utilizaram especialmente das tecnologias digitais de informação e comunicação - a criatividade foi a ferramenta - turmas inteiras foram transpostas para grupos de Whatsapp e Blogs pessoais tornaram-se meios de comunicação entre escola e comunidade, as redes sociais (Instagram e Facebook) tornaram-se uma possibilidade de comunicação entre professores, estudantes e os próprios conteúdos objetos das aprendizagens.

Nunca me vi numa situação como essa, gerir toda uma escola de forma remota, sem contato direto com meus alunos, funcionários e professores, teve um dia que achei que meu celular iria explodir. As aulas foram todas para as redes sociais, os professores criavam grupos em suas redes sociais e ali postavam os conteúdos, recebiam as atividades dos alunos, davam os retornos necessários. Não tínhamos uma plataforma própria para isso - como temos agora - tivemos que nos virar (Diretora da Escola $\Omega$ ).

A indicação do ensino remoto emergencial trouxe a possibilidade de um aprendizado mais significativo para além dos muros da escola, os estudantes poderiam fazer a gestão do seu tempo de estudos e aproveitamento, a sala de aula deixou de ser um lugar físico, podendo ser na prática em qualquer lugar e em qualquer momento do próprio tempo e do espaço. Mas a realidade da escola pública se mostrou feroz nesse sentido, começando pela categoria analítica mais básica do processo educativo: o acesso. Tem-se uma ideia no senso comum que todos os sujeitos desfrutam da conectividade, todos e todas possuem o instrumental para essa conexão com o mundo virtual. Indicamos aqui um recurso tecnológico bastante simples como os aparelhos de celular, haviam alunos sem essa tecnologia, e quando as tinham deveria ser compartilhada entre outros membros da família para a realização das atividades didático-pedagógicas.

Como cobrar de um aluno que faça as atividades se o único celular da família é o da mãe diarista, que sai de casa às 6hs da manhã e retorna ao final da tarde? Como cobrar de um aluno que entregue as atividades nos prazos se ele precisa dividir esse único celular com seus irmãos que também possuem atividades em suas escolas? Como exigir essa postura dos alunos? (Diretora da Escola $\Delta$ ). 
O acesso democrático da internet se mostrou uma verdadeira falácia segundo a Diretora da Escola $\Delta$, pois ter acesso a Whatsapp e Instagram não significa a conectividade com as possibilidades do mundo virtual. Ao relatar essa preocupação a diretora ressalta "Os alunos, aqueles maiores tinham aparelhos celulares defasados com conexão limitada a alguns aplicativos, ou seja, a sua capacidade de acesso aos materiais foi reduzida drasticamente, e enquanto equipe diretiva só nos demos conta muito tempo depois". Sendo que ainda nesse conjunto haviam estudantes sem acesso nenhum a esse tipo de suporte tecnológico, e com as medidas de enfrentamento a pandemia (como o importante e necessário distanciamento social), naquele momento estes sujeitos ficaram sem contato nenhum com a estrutura da escola, configurando apenas um número e se apresentando a margem de todo o processo educativo como salientou o Diretor da Escola $\beta$ "Fomos cobrados para a manutenção dos serviços da escola, não tínhamos estrutura para isso, como iremos atrás desses alunos e das famílias".

Inevitavelmente neste cenário conturbado há o elemento da formação $e$ da instrumentalização no uso dos recursos digitais, como uma nova exigência pedagógica. $\mathrm{O}$ fomento a esta nova realidade não realizado inicialmente pela rede pública, ocorreu como um movimento interno buscando justamente garantir ao menos essa dimensão do direito à educação ao maior número possível de estudantes. "Eu tinha professores no meu quadro que não conseguiam mexer no Whatsapp, imagina dar uma a distância", indica a Diretora da Escola $\Delta$, "Viemos de uma greve muito desgastada, perdemos muito e sem nenhuma perspectiva de melhora, fica difícil cobrar dos meus colegas estímulo" aponta o Diretor da Escola $\Omega$. "Mesmo repondo todos os dias da greve de 2019 fomos descontados do nosso salário, exigir dos colegas um compromisso com a escolas e os alunos foi muito difícil", complementa o Diretor da Escola $\beta$.

Neste momento da pandemia, as ações estavam desarticuladas na rede estadual tendo reflexos profundos na organização do trabalho pedagógico das instituições de ensino para além das questões de formação docente, a garantia do direito à educação fratura-se, especialmente quando observamos nesse cenário questões relativas à qualidade. A instrumentação dos professores foi realizada à revelia do Governo do Estados, nesse momento, alguns docentes se viram obrigados a comprar equipamentos tecnológicos e digitais novos que atendessem a nova demanda profissional, alteraram planos/pacotes de internet para que a nova capacidade acompanha-se o aumento da demanda de trabalho, o tempo ficou relativo às 4ohs semanais de trabalho triplicaram em alguns momentos, sem que nenhum estímulo por parte do Estado fosse indicado, pelo contrário, às demandas na produção de dados planilhados e índices de produtividade só aumentava. 
Me lembro de um momento que simplesmente eu não aguentei mais! Passava pelo menos 12 horas entre meu celular e meu computador, acabei comprando um computador melhor, mas rápido pra eu poder atender os professores e os alunos da escola. A dinâmica escolar não se restringe apenas às aulas, agora imagina como foi a emissão dos documentos escolares, os secretários da escola usaram seus equipamentos para ajudar (Diretor da Escola $\beta$ ).

Infelizmente as ações desarticuladas levam ao movimento de precarização do trabalho docente junto a rede pública estadual de educação, professores não tinham suas cargas horárias respeitadas, utilizavam recursos pessoais na consecução de suas aulas (computadores, planos de internet, periféricos de mídia, entre outros). A precarização o trabalho chegou com força total junto às escolas como indica o Diretor da Escola $\beta$ “Alguns colegas não tinham condições de ministrar aulas remotas, muitos não tinham computadores compatíveis, sem câmera, sem microfone, tiveram que comprar esses equipamentos por conta própria”. Já a Diretora da Escola $\Delta$ é categórica ao afirmar que "Mesmo mobilizando o material da escola para os professores isso foi insuficiente, nossa escola tem 5 notebooks para 47 professores revezarem, impossivel!”.

Foi uma situação muito complicada, porque além das aulas serem remotas, nossa fragilidade com o desmantelamento da nossa carreira, os descontos consecutivos do nosso contracheque devido à greve, nossa debilidade mental naquele momento de pânico e medo que vivemos no começo, o 'aumento' da nossa carga horária de trabalho, nossa! Foi um conjunto de coisas que aconteceram, não tinha como pensar que o trabalho que desenvolvemos naquele momento era positivo $e$ significativo (Diretor da Escola $\Omega$ ).

A qualidade social da educação nesse cenário ficou comprometida, da mesma forma que a efetivação do direito à educação, pois a própria organização do trabalho pedagógico desenvolvido por essas escolas, neste momento, estava deficitária. Os elementos elencados por Camini (2001) e Flach (2012) de democratização do acesso, democratização do conhecimento, democratização da gestão, financiamento e regime de colaboração, e valorização dos trabalhadores da educação ficaram em segundo plano. Nesse cenário, a noção da participação popular nos processos de gestão se perdeu, juntamente com a substituição dos recursos adequados para os recursos possíveis.

"Pensar no direito à educação de qualidade social não é focar apenas na presença do
aluno na escola, significa pensar todos os processos dos alunos na constituição da sua
própria cidadania. Agora realizar essa tarefa sem o mínimo apoio de nossa
mantenedora é um grande desafio" (Diretora da Escola $\Omega$ ).

A desarticulação entre o trabalho desenvolvido pelas escolas da rede e os desejos e anseios do Governo do Estado rompeu a necessária relação de responsabilização partilhada no fazer da escola, esse elo quebrado inviabiliza o trabalho desenvolvido pelas instituições escolares. A escola não é um mundo à parte, é um elemento agregador de professores e 
estudantes em uma comunidade escolar, e essa unidade relaciona-se com outras tantas presentes e existentes em uma rede, que por sua vez, dependem e demandam de uma unidade ainda maior, o poder do Estado.

Aquele início foi bastante complicado, a Secretaria da Educação não nos dava nenhuma dica de como tínhamos que fazer, erramos bastante, o trabalho que fizemos foi na intuição. Não fizemos o melhor dos nossos trabalhos, mas fizemos o que conseguimos fazer (Diretora da Escola $\Omega$ ).

Na escola o que nos pegou foi a falta de estrutura, mal tínhamos computadores na escola e simplesmente fomos jogados em uma outra realidade, contamos com a ajuda da comunidade escolar, mesmo assim foi bastante difícil. Foram cobranças de todos os lados, dos pais, dos alunos e da sociedade, pois achavam que tínhamos 'esticado' nossa greve (Diretor da Escola $\beta$ ).

Aprendemos a fazer as coisas do nada, do zero, o foco deixou de ser a aprendizagem e passou a ser 'oferecer alguma coisa' para nossos alunos, triste isso. Tanto que agora de forma mais estruturada com orientações claras do governo, com o uso de uma plataforma planejada e pensada para atender as necessidades das escolas, com formação em tecnologias, estamos resgatando e tentando arrumar a bagunça que tivemos em 2020 (Diretora da Escola $\Delta$ ).

As escolas ainda buscam a retomada do tempo perdido, os primeiros 75 (setenta e cinco) dias do início da pandemia, impactou a educação gaúcha por diferentes frentes. Considerando que a maior parte dos alunos se situam em regiões de vulnerabilidade social onde a escola não se dedica apenas em auxiliar os sujeitos a assimilação de conhecimentos historicamente produzidos pelas sociedades, é também um importante elemento integrante de políticas setoriais articuladas, retratando em alguma medida os esforços de ligação e integração de políticas públicas. Como afirma Junqueira (1999, p. 29), ao Estado fica evidente e necessário desenvolver "nova maneira de planejar, executar e controlar a prestação de serviços para garantir o acesso igual dos desiguais”.

\section{Considerações Finais}

A pandemia do novo coronavírus da mesma forma que desvela o abismo educacional presente no Brasil, tornou-se potência para o incremento de diferentes possibilidades educativas na emergência da contingência da oferta educacional no cenário pandêmico. Os processos educativos passaram por um novo regime de significação, muitos ancorados em tecnologias na efetivação do ensino remoto, todavia, o processo educativo não se configura apenas na relação educando-educador, outras dimensões também se apresentam como partes fundamentais na efetivação dos objetivos pedagógicos das instituições de ensino, como é o caso da gestão educacional e do papel ocupado por cada elemento da comunidade escolar na consecução dos objetivos educacionais. Partindo desta premissa, a investigação apresentada 
buscou evidenciar os primeiros movimentos da relação estado-escola no contexto da pandemia do novo coronavírus, no Estado do Rio Grande do Sul, à luz da efetivação do direito à educação com qualidade social pelo olhar de equipes diretivas de escolas da rede.

No primeiro momento da chegada da pandemia no estado do Rio Grande do Sul, houveram severas falhas na comunicação entre o Estado-Sociedade na efetivação do desenvolvimento do trabalho pedagógico a ser desenvolvido pela sua rede de educação. O direito à educação de qualidade ficou comprometido, pois para além da não mobilização de recursos imediatos para esta garantia, não houve uma articulação efetiva junto ao plano de contingência sanitário que considera-se ou ao menos incorpora-se a necessidade de se (re)pensar o arranjo escolar neste momento particular da história. É entendível que a suspensão das atividades escolares presenciais fora o melhor encaminhamento por parte do Estado, porém apenas a indicação da implementação do ensino remoto sem planejamento e organização articulada na própria rede de educação configura-se como a maior falha da gestão governamental.

Diretores de escolas da rede mobilizaram seus recursos na garantia da efetivação do direito à educação à sua maneira, carecendo de uma orientação clara e objetiva dos encaminhamentos necessários para tanto. A mobilização das ações, a formação dos professores, o atendimento aos estudantes, o suporte técnico e instrumental necessário, a dinâmica escolar em sua forma mais geral ficou a cargo das escolhas dos diretores escolares. A qualidade social nesse sentido foi relegada a um segundo plano, pois o foco nesse processo pautou-se na oferta educativa ao maior número de estudantes possíveis, consequentemente o atendimento das demandas das comunidades escolares passou a desconsiderar as suas necessidades imediatas.

Atualmente o engendramento da relação estado-escola se estabelece de outra forma, as ações dentro da rede são articuladas de forma conjunta, respeitando a autonomia das instituições de ensino, coordenadas e orientadas. A organização do trabalho pedagógico por parte da Secretaria Estadual de Educação possibilitou o uso de uma única plataforma digital na operacionalização do ensino remoto pelas escolas da rede de educação, ao atendimento aos estudantes com a distribuição de kit de merenda, alterações no calendário letivo, materiais impressos e financiamento de internet para os estudantes da rede, utilização de mídias digitais e outras plataformas de comunicação (como a televisão) para o desenvolvimento da complementaridade das atividades pedagógicas e a retomada gradual das atividades presenciais nas escolas, a partir do modelo de ensino híbrido.

A gestão da escola efetiva-se como o instrumental do Estado na consecução das suas políticas e da sua percepção/intencionalidade com relação ao papel da educação no desenvolvimento da região, a carência de orientações fez com as escolas se colapsassem 
em sua maioria, considerando ainda que antes da pandemia as instituições já careciam de uma série de necessidades como o aumento do quadro dos profissionais da educação, recursos financeiros para melhoria dos espaços e manutenção de outros, aquisição de equipamentos no apoio às atividades didático pedagógicas, além de uma concepção institucionais de valorização do trabalho docente.

A crise trazida com a pandemia do novo coronavírus efetivou-se igualmente como uma crise institucional, onde as escolas tiveram que se reinventar nas suas mais variadas dimensões estruturais, cabendo ao Estado o fomento a essas mudanças com foco no atendimento dos estudantes. A demora na articulação da relação estado-escola fez com que as dificuldades advindas do combate ao covid-19 fossem potencializadas, especialmente se considerarmos o impacto do ensino remoto em todo o cotidiano da escola, para toda a comunidade escolar. Diretamente caiu sobre os ombros das equipes diretivas os encaminhamentos de organização dos processos da rede (de forma individualizada e desorganizada), a partir da omissão do Estado em capitanear os direcionamentos de enfrentamento às dificuldades imperativas a este momento da história.

Esta investigação não teve por objetivo apontar estratégias no enfrentamento às dificuldades educacionais ocorridas nesse período, ou ainda culpabilizar o estado pelo fracasso da sua estratégia omissa nos direcionamentos iniciais relativos às demandas educativas no Estado do Rio Grande do Sul, muito pelo contrário, o foco aqui foi evidenciar como a pandemia do novo coronavírus acabou impactando profundamente a leitura social do trabalho desenvolvido no interior da instituição escolar em suas mais variadas dimensões associadas, é importante o registro das percepções deste momento sui generis que experienciamos enquanto sociedade.

O contexto pandêmico evidenciou o quanto é importante o papel e a atuação do Estado na garantia do direito à educação, a sua falta impacta diretamente no trabalho desenvolvido pelas escolas públicas. A qualidade social da educação emerge como uma importante pauta no debate do que chamamos de uma nova perspectiva educacional no cenário (pós)pandemia. O direito à uma educação pública de/com qualidade social deve ser preservado, pois são nesses momentos de crise que percebemos a importância da escola não apenas na formação técnica de caráter instrumental, mas também aquela que incorpore em suas práticas a valorização do conhecimento simbólico e sensível para uma educação emancipadora.

\section{Referências}

ALVES, L. Educação Remota: Entre a Ilusão e a Realidade. Interfaces Científicas, v. 8, n. 3, p. 348-365, 2020. Disponível em: https://cutt.ly/lmlSeYZ. Acesso em: 20 jun. 2021. DOI: https://doi.org/10.17564/2316-3828.2020v8n3p348-365. 
BRASIL, Medida Provisória 934 de 1 de abril de 2020a. Estabelece normas excepcionais sobre o ano letivo da educação básica e do ensino superior decorrentes das medidas para enfrentamento da situação de emergência de saúde pública de que trata a Lei no 13.979, de 6 de fevereiro de 2020. Disponível em: https://cutt.ly/lmlANYC. Acesso em: 30 jun. 2021.

BRASIL. Constituição Federal 1988. Constituição da República Federativa do Brasil. Disponível em: https://cutt.ly/umlA 1mc. Acesso em: 20 jun. 2021.

BRASIL. Lei Federal n ${ }^{\circ}$ 9.394, de 20 de dezembro de 1996. Estabelece as diretrizes e bases da educação nacional. Disponível em: https://cutt.ly/WmlA2Ya. Acesso em: 20 jun. 2021.

BRASIL. Ministério da Educação. Parecer Conselho Nacional de Educação Conselho Pleno $n^{\circ}$ 05/20. Reorganização do Calendário Escolar e da possibilidade de cômputo de atividades não presenciais para fins de cumprimento da carga horária mínima anual, em razão da Pandemia da COVID-19. Brasília, DOU, ano CLVIII, nº 83, 2020 b.

CAMINI, L. et al. Educação pública de qualidade social: conquistas e desafios. Petrópolis: Vozes, 2001.

CELlarD, A. A Análise Documental. In: POUPART, J. et al. A Pesquisa Qualitativa: Enfoques Epistemológicos e Metodológicos. Petrópolis, Vozes, 2008.

CERVO, A. L.; BERVIAN, P. A. Metodologia científica. São Paulo: Prentice Hall, 2002.

CURY, C. R. J. A Educação como Desafio na Ordem Jurídica. In: LOPES, E. M. T.; FILHO; L. M. F.; VEIGA, C. G. 500 Anos de Educação no Brasil. Belo Horizonte: Autêntica, 2010.

DOURADO, L. D.; OLIVEIRA, J. F.; SANTOS, C. A. A Qualidade da Educação: conceitos e definições. Instituto Nacional de Estudos e Pesquisas Educacionais Anísio Teixeira, Série Documental Textos para Discussões, 2007.

DOURADO, L. F.; OLIVEIRA, J. F. A qualidade da educação: perspectivas e desafios. Cadernos Cedes, v. 29, n. 78, p. 201-215, 2009. Disponível em: https://cutt.ly/amlStTg. Acesso em: 2- jun. 202 1. DOI: https://doi.org/10.1590/s0101-32622009000200004.

DUARTE, C. S. A Educação como um Direito Fundamental de Natureza Social. Revista Educação Social, v. 28, n. 100, p. 691-713, 2007. Disponível em: https://cutt.ly/umlSChX. Acesso em 20 jun. 2021. DOI: https://doi.org/10.1590/s0101-73302007000300004.

FARENZENA, N. A Emenda da obrigatoriedade: mudanças e permanências. Revista Retratos da Escola, v. 4, n. 7, p. 197-209, 2010. Disponível em: https://cutt.ly/bmlSaVn. Acesso em: 20 jun. 2021.

FÁvero, A. A.; CENTENARO, J. B. A Pesquisa Documental nas Investigações de Políticas Educacionais: Potencialidades e Limites. Revista Contrapontos, v. 19, n. 1, p. 170-184, 2019. Disponível em: https://cutt.ly/5mlSfod. Acesso em: 20 jun. 2021. DOI: https://doi.org/10.14210/contrapontos.v19n1.p170-184.

FLACH, S. de. F. Contribuições Para o Debate Sobre a Qualidade Social da Educação na Realidade Brasileira. Contexto E̊ Educação, ano 27, nº. 87, p. 4-25, 2012. Disponível em: https://cutt.ly/ymlSh4U. Acesso em: 20 jun. 2021.

FONSECA, J. J. S. Metodologia da pesquisa científica. Fortaleza: UEC, 2002. 
FONTOURA, J. S. D. de. A. A qualidade social da Educação Superior no contexto emergente dos Institutos Federais: uma abordagem na perspectiva da política pública. 336 fls. Tese (Doutorado em Educação), Universidade do Vale do Rio dos Sinos - UNISINOS, 2021. Disponível em: https://cutt.ly/nmlSlWw. Acesso em 20 jun. 2021.

FREITAS, A. R. R; NAPIMOGA, M.; DONALISIO, M. R. Análise da gravidade da pandemia de Covid-19. Epidemiologia e Serviços de Saúde, v. 29, n. 2, p. 1-5, 2020. Disponível em: https://cutt.ly/UmlSxLI. Acesso em: 20 jun. 2021. DOI: https://doi.org/10.5123/s1679-49742020000200008.

GADOTTI, M. Qualidade na educação: uma nova abordagem. São Paulo: Editora e Livraria Instituto Paulo Freire, 2010.

GZH Política. Após 57 dias, professores estaduais encerram greve. Magistério - Matéria 14/01/2020. Disponível em: https://cutt.ly/KmlSvLu. Acesso em 20 jun. 2021

HAGUETTE, T. M. F. Metodologias Qualitativas na Sociologia. 9. ed. Petrópolis: Vozes, 2003.

JAKIMIUI, V. C. de. L. O Direito à Educação no Contexto da Pandemia (Covid-19) no Brasil: Projetos de Formação em Disputa. Revista Interinstitucional Artes de Educar, v. 6, p. 94117, 2020. Disponível em: https://cutt.ly/5mlSQxz. Acesso em 20 jun. 2021 1. DOI: https://doi.org/10.12957/riae.2020.51007.

JUNQUEIRA, L. A. P. Descentralização, intersetorialidade e rede como estratégias de gestão da cidade. Revista FEA/PUC-SP, v. 1, p. 57-72, nov. 1999. Disponível em: https://cutt.ly/6mlSIMy. Acesso em: 20 jun. 2021.

MARX, K. Manuscritos Econômico-Filosóficos. Tradução Jesus Ranieri, São Paulo: Boitempo, 2008.

MORAES, R; GALIAZZI, M. C. Análise Textual Discursiva. Ijuí: Editora Unijuí, 2011.

OLIVEIRA, R. P. de. O direito à Educação. In: OLIVEIRA, R. P. de.; ADRIÃO, T. (Org.). Gestão, financiamento e direito à educação: análise da LDB e da Constituição Federal. São Paulo: Xamã, 2001.

ORGANIZAÇÃO DAS NAÇÕES UNIDAS - ONU. Declaração Universal dos Direitos Humanos, 1948. Disponível em: https://cutt.ly/FmlSP2a. Acesso em: 30 jun. 2021.

RIO GRANDE DO SUL, Conselho Estadual de Educação. Parecer n ${ }^{\circ}$ 01/20. Orienta as Instituições integrantes do Sistema Estadual de Ensino sobre o desenvolvimento das atividades escolares, excepcionalmente, enquanto permanecerem as medidas de prevenção ao novo Coronavírus COVID-19. Porto Alegre, DOE, ano LXXVIII, n 55, 2020 a.

RIO GRANDE DO SUL, Decreto $\mathrm{n}^{\circ}$ 54.875, de 21 de novembro de 2019. Fixa normas gerais para o calendário escolar da rede estadual de ensino para o ano letivo de 2020. Disponível em: https://cutt.ly/umlSSGL. Acesso em 1 jul. 2021.

RIO GRANDE DO SUL, Decreto n ${ }^{\circ} 55.118$, de 16 de março de 2020b. Estabelece medidas complementares de prevenção ao contágio pelo COVID-19 (novo Coronavírus) no âmbito do Estado. Disponível em: https://cutt.ly/FmlSDOz. Acesso em 1 jul. 2021. 
RIO GRANDE DO SUL, Decreto $n^{\circ}$ 55.154, de 1 de abril de 2020c. Reitera a declaração de estado de calamidade pública em todo o território do Estado do Rio Grande do Sul para fins de prevenção e de enfrentamento à epidemia causada pelo COVID-19 (novo Coronavírus), e dá outras providências. Disponível em: https://cutt.ly/omlSGyA. Acesso em 1 jul. 2021.

RIO GRANDE DO SUL, Decreto ${ }^{\circ} 55.220 / 20$, de 30 de abril de 2020d. Altera o Decreto $n^{\circ}$ 55.154, de $1^{\circ}$ de abril de 2020, que reitera a declaração de estado de calamidade pública em todo o território do Estado do Rio Grande do Sul para fins de prevenção e de enfrentamento à epidemia causada pelo COVID-19 (novo Coronavirus), e dá outras providências. Disponível em: https://cutt.ly/VmlSHP8. Acesso em 1 jul. 2021.

RIO GRANDE DO SUL, Secretaria Estadual da Saúde. Confirmado o primeiro caso de novo coronavírus no Rio Grande do Sul. Comunicação - Notícias: 10/03/2020e. Disponível em: https://cutt.ly/ymlSJ1Z. Acesso em 02 jul. 2021.

UNA-SUS, Ministério da Saúde. Coronavírus: Brasil confirma primeiro caso da doença. Disponível em: https://cutt.ly/FmlSLWC. Acesso em 07 jul. 2021. 